\section{Author Correction: Extreme rainfall triggered the 2018 rift eruption at Kîlauea Volcano}

https://doi.org/10.1038/s41586-020-2356-z

Correction to: Nature https://doi.org/10.1038/s41586-020-2172-5

Published online 22 April 2020

Check for updates

Jamie I. Farquharson \& Falk Amelung

In the abstract of this Article, "consistent with the lack of precursory summit inflation" should have read "consistent with the lack of substantial precursory summit inflation", because a small amount (2-3 $\mathrm{cm}$ ) of localized summit inflation was detected with GPS starting about two weeks before the eruption. This has implications for intrusion terminology. The subtle uplift signal indicates that the intrusion was not solely "passive," as we referred to it in this Article; rather, it was hybrid intrusion ${ }^{1}$ caused by both a decrease in the extensional stress (owing to pore fluids in this case) and magma pressurization, the latter smaller than in the previous hybrid intrusion. This suggests that infiltrating rainwater was not the only factor influencing the intrusion. The sentence on page 492 "The lack of precursory summit and rift-zone inflation suggests that the intrusion-eruption was not triggered by an influx of fresh magma from depth but that it was a passive intrusion, caused by extension and/or weakening of the rift zone" should read "The lack of precursory summit and rift-zone inflation suggests that the intrusioneruption was not dominated by an influx of fresh magma from depth but that it was a hybrid intrusion, caused primarily by extension and/or weakening of the rift zone" and the sentence on page 493 "The absence of widespread precursory inflation suggests that the 2018 intrusion was passive, fostered by weakening of the rift zone." should read "The absence of widespread precursory inflation suggests that the 2018 intrusion was predominantly fostered by weakening of the rift zone.". Our main conclusion that rainfall-induced pore pressure changes affected the initiation of the 2018 intrusion remains unchanged.

In addition, "most rainfall occurs between 9 March and 25 August" should read "most rainfall occurs between 16 August and 5 March", as can be seen in Fig. 2c. This does not affect our results because the correct thresholds are used in the analysis shown in Extended Data Fig. 3 and provided in the associated code.

There is also an error regarding the 1924 activity. The eruption occurred in May but lava lake subsidence occurred in February ${ }^{2}$. Directly linking the extreme rainfall observed in April 1924 to the onset of the eruptive period-as we originally suggested in the Article-is thus inappropriate. However, with a February start date this eruption falls in the 'wet' part of the year. With this change, 37/62(60\%) eruptions fall within the wettest part of the year, including all $(5 / 5,100 \%)$ VEI $2+$ eruptions. Extended Data Fig. 3 has been corrected accordingly and Fig. 1 of this Amendment shows the incorrect, as-published Extended Data Fig. 3 as well as the corrected figure, for transparency. In the legend of Extended Data Fig. 3, the sentence "The observed number of historical 'wet' season eruptions (36) is highlighted, with a probability of 0.04 ." should read "The observed number of historical 'wet' season eruptions (37) is highlighted, with a probability of $\mathbf{0 . 0 2 . . " ~ F o r ~ b o t h ~ s e t s ~ o f ~ e r u p t i o n s , ~ t h e s e ~}$ values represent a statistically significant deviation from the expected distribution (2 standard deviations from the mean), which strengthens our argument that the majority of eruptions are initiated during the wettest times of the year. The sentence on page 493 "Finally, historical precipitation records show that Kilauea's May 1924 eruption-the previous extraordinary eruption-also followed extremely wet conditions." should read "Finally, historical precipitation records show that Kîlauea's May 1924 eruption-the previous extraordinary eruption-also involved extremely wet conditions." We regret these errors, and thank M. Poland and his USGS colleagues for bringing them to our attention.

Finally, owing to a production error, the $y$-axis units of Fig. 2c, e should be millimetres rather than metres, and the leftmost part label 'd' should be 'e'. All of these errors have been corrected online.

\footnotetext{
1. Poland, M. P., Miklius, A. \& Montgomery-Brown, E. K. Magma supply, storage, and transport at shield-stage Hawaiian volcanoes. In Characteristics of Hawaiian Volcanoes Vol. 1801, 179-234 (US Geological Survey, 2014).

2. Jaggar, T. A. \& Finch, R. H. The explosive eruption of Kilauea in Hawaii, 1924. Am. J. Sci. 8, 353-374 (1924).
}

Incorrect, as-published Extended Data Fig. 3

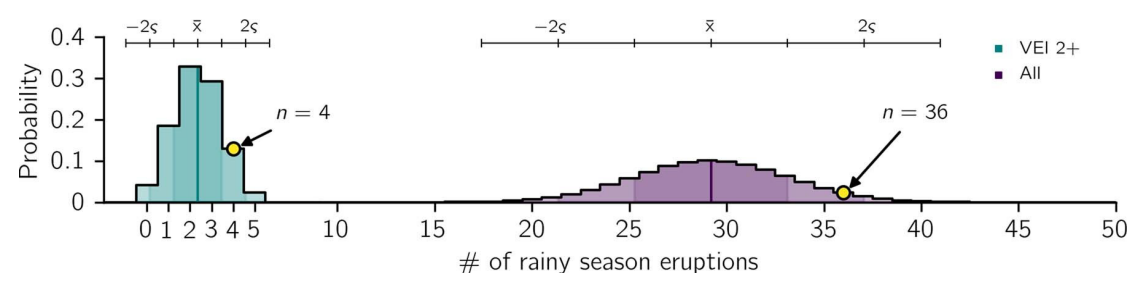

Corrected Extended Data Fig. 3

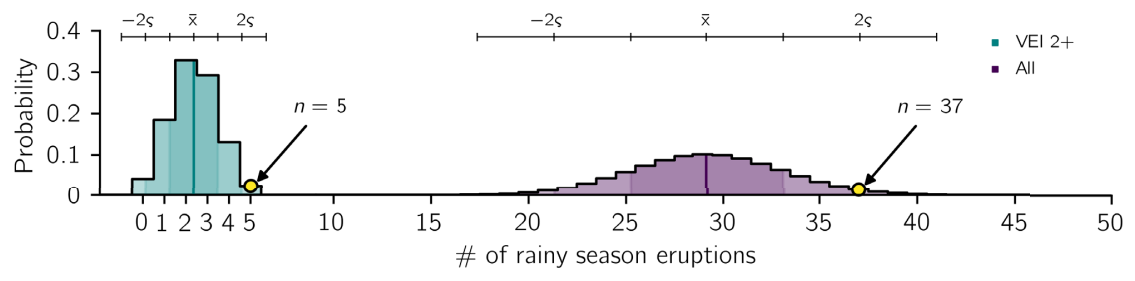

Fig. 1 This figure shows the incorrect, as-published Extended Data Fig. 3, and the corrected version. 